\title{
artigo
}

\section{Análise descritiva da cobertura vacinal executada pelo programa nacional de imunizações entre 2015 e 2019}

Descriptive analysis of vacinal coverage performed by the national immunization program between 2015 and 2019 Análisis descriptivo de la cobertura vacinal realizada por el programa nacional de inmunizaciones entre 2015 y 2019

\section{RESUMO}

Objetivo: Realizar uma análise descritiva da cobertura vacinal executada pelo programa nacional de imunizações entre 2015 e 2019. Método: Foi realizado um estudo descritivo, com base nas informações epidemiológicas das coberturas vacinais do Brasil. Foram utilizadas variáveis como Cobertura Nacional, Cobertura por Região, Média das taxas de Cobertura entre Regiões e Média de Cobertura entre Estados. Resultados: Em 2015 a taxa de cobertura vacinal alcançou 95,7\%, valor superior ao ideal. Os anos subsequentes apresentaram brusco rebaixamento dessa taxa com 50,44\% em 2016, 69,04\%, em 2017 e 71,99\% em 2018. 2019 manifestou apenas 45,65\%. A Região Sul, obteve a maior média (72,20\%), enquanto a Região Norte $(61,28 \%)$, com a menor taxa. Conclusão: 0 cenário é comprometedor no tocante ao controle das doenças imunopreveníveis, reflete a necessidade de aprimorar a comunicação entre profissionais e a população, a fim de unificar e promover informações corretas e seguras sobre a vacina.

DESCRITORES: Programas de Imunização; Cobertura Vacinal; Políticas de Saúde.

\section{ABSTRACT}

Objective: To carry out a descriptive analysis of vaccination coverage performed by the national immunization program between 2015 and 2019. Method: A descriptive study was conducted, based on epidemiological information on vaccination coverage in Brazil. Variables such as National Coverage, Coverage by Region, Average Coverage rates between Regions and Average Coverage between States were used. Results: In 2015, the vaccination coverage rate reached $95.7 \%$, higher than the ideal value. Subsequent years showed a sharp decrease in this rate with $50.44 \%$ in $2016,69.04 \%$ in 2017 and $71.99 \%$ in 2018. 2019 showed only $45.65 \%$. The South Region had the highest average $(72.20 \%)$, while the North Region $(61.28 \%)$, with the lowest rate. Conclusion: The scenario is compromising with regard to the control of vaccine-preventable diseases, reflects the need to improve communication between professionals and the population, in order to unify and promote correct and safe information about the vaccine.

DESCRIPTORS: Immunization Programs, Vaccination Coverage; Health Policy.

\section{RESUMEN}

Objetivo: Realizar un análisis descriptivo de las coberturas de vacunación realizado por el programa nacional de inmunización entre 2015 y 2019. Método: Se realizó un estudio descriptivo, con base en información epidemiológica sobre coberturas de vacunación en Brasil. Se utilizaron variables como Cobertura Nacional, Cobertura por Región, Tasas de Cobertura Media entre Regiones y Cobertura Media entre Estados. Resultados: En 2015, la tasa de cobertura de vacunación alcanzó el 95,7\%, superior al valor ideal. Los años posteriores mostraron una fuerte disminución en esta tasa con 50,44\% en 2016, 69,04\% en 2017 y $71,99 \%$ en 2018. 2019 mostró solo 45,65\%. La Región Sur tuvo el promedio más alto (72,20\%), mientras que la Región Norte $(61,28 \%)$, con la tasa más baja. Conclusión: El escenario es comprometedor en cuanto al control de enfermedades prevenibles por vacunación, refleja la necesidad de mejorar la comunicación entre profesionales y población, con el fin de unificar y promover información correcta y segura sobre la vacuna.

DESCRIPTORES: Programas de Inmunización; Cobertura de Vacunación; Política de Salud.

RECEBIDO EM: 30/09/2020 APROVADO EM: 04/11/2020

\section{Lúcia Magnólia Albuquerque Soares de Camargo}

Professora do Curso de Enfermagem, UNIFACISA. Coordenadora da Liga Acadêmica de Saúde Coletiva de Enfermagem - LASCEN. Mestre em Saúde Coletiva. Especialista em Gestão de Serviços de Saúde e Adm. Hospitalar, Saúde do Trabalhador e Saúde Pública. Enfermeira.

ORCID: 0000-0002-5442-8227 
Lara Kamylli Felismino Chagas

Presidente LASCEN. Graduanda do Curso de Enfermagem UNIFACISA.

ORCID: 0000-0002-7505-5036

\section{INTRODUÇÃO}

0 termo vacina é definido como "um produto que produz imunidade e, portanto, protege o organismo contra as doenças", pelo Centro de Controle e Prevenção de Doenças (Centers for Disease Control and Prevention - CDC), e representa uma substância biológica extremamente segura, sendo responsável por grandes benefícios para a saúde pública. Deste modo, dois termos são utilizados de maneira equivalente: vacinação e imunização, no qual vacinação é a administração de micro-organismos infecciosos ou partes destes, mortos ou atenuados, com o finalidade de prevenção da doenças em virtude da formação de anticorpos, e imunização é o processo pelo qual o indivíduo torna-se protegido contra uma determinada doença ${ }^{(1)}$.

Tendo em vista que a imunização é o objetivo da vacinação, ou seja, provendo ao indivíduo vacinado imunidade contra determinada doença, por meio da administração do imunobiológico que propiciará a proteção, ou seja, vacinação é o ato de vacinar e imunização é a aquisição de proteção imunológica contra uma doença, geralmente infecciosa. A imunização por sua vez, pode ser ativa e passiva, no qual a ativa ocorre quando o próprio sistema imune do indivíduo, ao entrar em contato com uma substância estranha ao organismo (antígeno), responde produzindo anticorpos, podendo ser adquirida através da contaminação por uma doença infecciosa ou através da vacinação, ao contrário da imunização passiva, que é induzida pela administração de anticorpos contra uma infecção específica ${ }^{(2)}$.

A vacinação é destacada como um dos maiores feitos da saúde pública do século $\mathrm{XX}$, sendo considerada um dos três marcos supremos da saúde pública para promoção, prevenção e controle das doenças imunopreveníveis, tornando-se uma das medidas de prevenção mais efetivas e efi- cientes para os sistemas de saúde. É indiscutível a relevância que as vacinas possuem na promoção à saúde e na prevenção de doenças imunopreveníveis, principalmente ao longo da infância. Diante desta perspectiva, as autoridades sanitárias, em todo o mundo, instituíram programas de imunizações, bem como calendários vacinais específicos conforme cada faixa etária ${ }^{(3,4)}$.

\section{O termo vacina}

é definido como

"um produto que

produz imunidade

e, portanto, protege

o organismo contra

as doenças", pelo

Centro de Controle

e Prevenção

de Doenças

(Centers for Disease

Control and

Prevention - CDC),
Essas características tornam a vacina um meio de intervenção lendário, com o intuito de diminuir a morbidade de doenças infectocontagiosas por meio de proteção coletiva, onde indivíduos imunes-vacinados protegem indiretamente os não vacinados, dificultando que o patógeno circule. A vacina foi capaz de mudar o cenário sanitário entre os séculos, destaca-se a década de 1930 , onde $45,7 \%$ das mortes eram devido a doenças infecciosas, passando para apenas para 4,35\% no ano de $2006^{(5)}$.

No Brasil, o Ministério da Saúde estabeleceu um amplo programa de imunização de rotina e promove, periodicamente, campanhas com o intuito de controlar e erradicar doenças mediante vacinação maciça de crianças. Declarada a erradicação da varíola em 1973, uma nova etapa da história iniciou-se com a instituição do Programa Nacional de Imunização - PNI, formalizado em 1975 pela lei $n^{\circ} 6.259$ e decreto $\mathrm{n}^{\circ} 78.23 / 76$, como também o Sistema Nacional de Vigilância Epidemiológica e Imunizações viabilizando a consolidação do PNI. Ainda na década de setenta, obteve o primeiro calendário básico de vacinação, com vacinas contra tuberculose, poliomielite, sarampo, difteria, tétano e coqueluche, sendo obrigatórias para os menores de um ano ${ }^{(6)}$.

A vigilância da cobertura vacinal, é uma ferramenta imprescindível para a avaliação do PNI, e sugere que a mesma tem viabilizado os inquéritos populacionais que propõem otimizar a cobertura vacinal no Brasil. O PNI é um dos maiores programas de imunização do mundo, chegando a ofertar 45 diferentes imunobiológicos para toda a população, de todas as idades ${ }^{(4)}$.

Os avanços do PNI com a descentralização das vacinas para os municípios, sendo integradas às Estratégias de Saúde da Família - ESF, e a Criação da Global Alliance for Vaccine and Immunization GAVI, os calendários nacionais de vacina se tornando mais amplos, compostos de 
imunobiológicos e atuação de qualificada e ativa de equipe vacinadora, refletiram nas altas porcentagens de cobertura de imunização em todo país ${ }^{(5)}$.

O programa que se tornou referência mundial em imunização, após décadas com taxas de boa adesão popular, vem apresentando declínio nos percentuais de vacinação. Desde fevereiro de 2018, até 21 de janeiro deste ano, foram confirmados 10.302 casos de sarampo no Brasil. Dos 5.570 municípios do país, 2.751 (49\%) não atingiram a meta de cobertura vacinal de sarampo, ficando longe do esperado de 95\% da cobertura. Destaca-se o estado do Pará, que apresentou $83,3 \%$ dos municípios fora dessa meta; Roraima com 73,3\% e Amazonas, com apenas 50\% de cobertura vacinal ${ }^{(7)}$. Após dois anos da conquista do certificado de país livre de sarampo, o Brasil identifica novos casos da doença em 2019, e perde o certificado em março, com 48 casos da doença. Em setembro, já eram 2.753 casos, um aumento de $18 \%$ nos $\operatorname{casos}^{(8)}$.

Tendo em vista esse cenário, a problemática de saúde pública põe em risco a população que ainda não possui idade para receber o imunobiológico ou é pertencente ao grupo que não possui condições de ser imunizado. Portanto, a presente pesquisa teve como objetivo, realizar uma análise descritiva da cobertura vacinal executada pelo programa nacional de imunizações entre 2015 e 2019.

\section{MÉTODO}

Foi realizado um estudo descritivo, com base nas informações epidemiológicas das coberturas vacinais do Brasil. Como critérios de inclusão, utilizou-se todos os dados nacionais de cobertura vacinal, de cada Região, e Estados da federação isoladamente, entre os anos de 2015 e 2019, disponibilizados abertamente no sítio eletrônico SI-PNI, do PNI e Departamento de Informática do SUS - DATASUS. Compuseram os critérios de exclusão os dados referentes as Campanhas Nacionais de Imunização entre o período proposto para o estudo. Os dados foram coletados em 13 de Julho de 2020.
Foram levantados dados que permitiram as analisadas das seguintes variáveis: Taxa de Cobertura Nacional, Taxa de cobertura por Região, Média das taxas de cobertura entre as Regiões Norte, Nordeste, Sul, Sudeste e Centro-Oeste, e Média de Cobertura entre os 26 Estados do território brasileiro, com destaque para os Estados com maior e menor taxa de cobertura por Região, ambas entre os anos de 2015 e 2019.

Após obtenção dos dados, os mesmos foram tratados através de cálculos de média simples e convertidos sob a forma de taxa de cobertura nacional. A partir dos dados tratados, foram confeccionados gráficos para uma melhor compreensão dos dados obtidos. Todos os dados foram processados usando o programa Excel for Windows 2010. Não foi necessário submeter o estudo para aprovação do Comitê de Ética em Pesquisa, tendo em vista que os dados utilizados são de domínio público e sem identificação de participantes.

\section{RESULTADOS}

\section{Cobertura Nacional}

No ano de 2015 a taxa de cobertura vacinal em todo território brasileiro apresentou uma taxa de $95,7 \%$, valor superior a taxa de $95 \%$ considerada ideal para manutenção imunização da população geral. $\mathrm{O}$ ano seguinte, 2016, apresentou um brusco rebaixamento de imunização, com apenas $50,44 \%$ de cobertura, aproximando-se do valor considerado a metade da taxa ideal. 2017 expressa o valor de $69,04 \%$ da taxa de cobertura, semelhante ao observado em 2018 , com $71,99 \%$ da população vacinada. Com dois anos de crescente cobertura, apesar de expressão tímida entre 2017 e 2018, não houve sequência positiva para retorno ao já apresentado em 2015. O ano de 2019 superou a baixa cobertura alcançada em 2016, manifestando apenas $45,65 \%$, demonstrando um valor competente a metade da taxa ideal de vacinação (FIGURA 1)

\section{Cobertura Regional}

Com o território de dimensóes continentais possuído pelo Brasil, suas regiões possuem diferentes resultados de cobertura de vacina, que nem sempre corroboram com o cenário apresentado nacionalmente. No ano de 2015, concomitantemente todas as regiões do país obtiveram a melhor taxa de cobertura dos cinco anos. As piores taxas, por sua vez, foram observadas em 2019, na maioria das regióes, sendo diferente apenas na região Sul, que possui pior taxa em 2016 (FIGURA 2). A média de cobertura das regióes durantes os anos de 2015 e 2019 representam: 61,28\% na Região Norte, com a menor taxa entre as

\section{FIGURA 1: Evolução da Cobertura Vacinal Nacional entre 2015 e 2019}

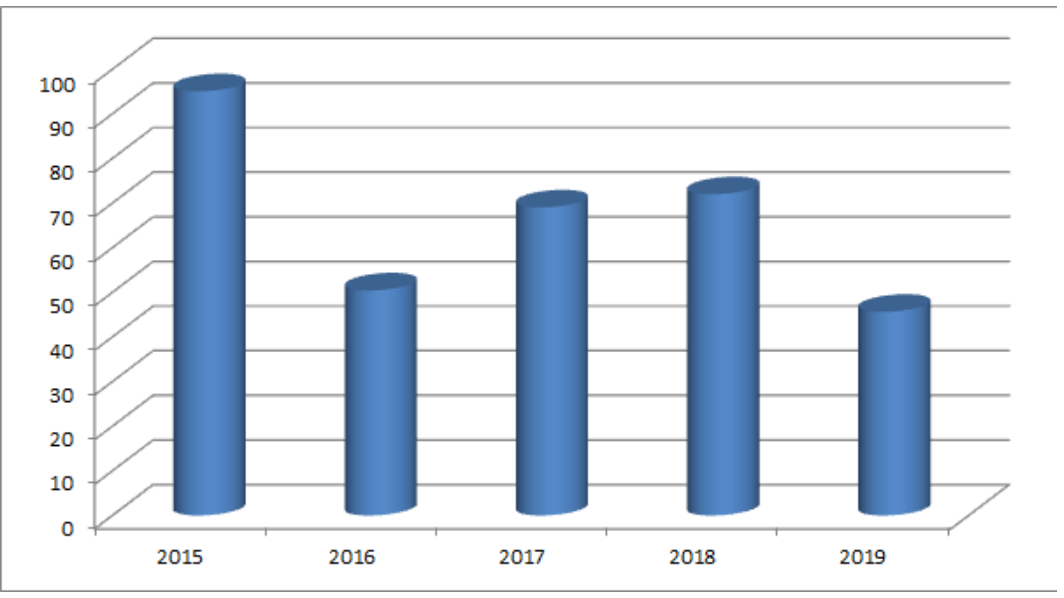

Fonte: DATASUS, 2020. 
regiões; Região Nordeste tendo 63,95\%; Região Sudeste com 66,79\%; Região Sul, com maior média $(72,20 \%)$, e Região Centro-Oeste, obtendo 70,71\%.

\section{Cobertura Estadual}

Com 26 estados componentes da federação brasileira, o estado de Santa Catarina lidera o ranking da cobertura vacinal entre os estados do país e da Região Sul, com média de 60,59\%, sendo o Rio Gran- de do Sul com a menor média $(51,65 \%)$ da Região. Enquanto o Rio de Janeiro possui a menor média dos estados e da Região Sudeste, com taxa de 25,99\%, e Minas Gerais com a maior média da Região (53,43\%), entre os anos de 2015 a 2019.

O Estado de Tocantins com 57,59\% expressou maior média de vacinação na Região Norte, enquanto o Amapá com $44,02 \%$ possui a menor, ficando abaixo de todos da Região. Rio Grande do Norte

\section{FIGURA 2: Cobertura Vacinal das Regiões Brasileiras entre 2015 e 2019}

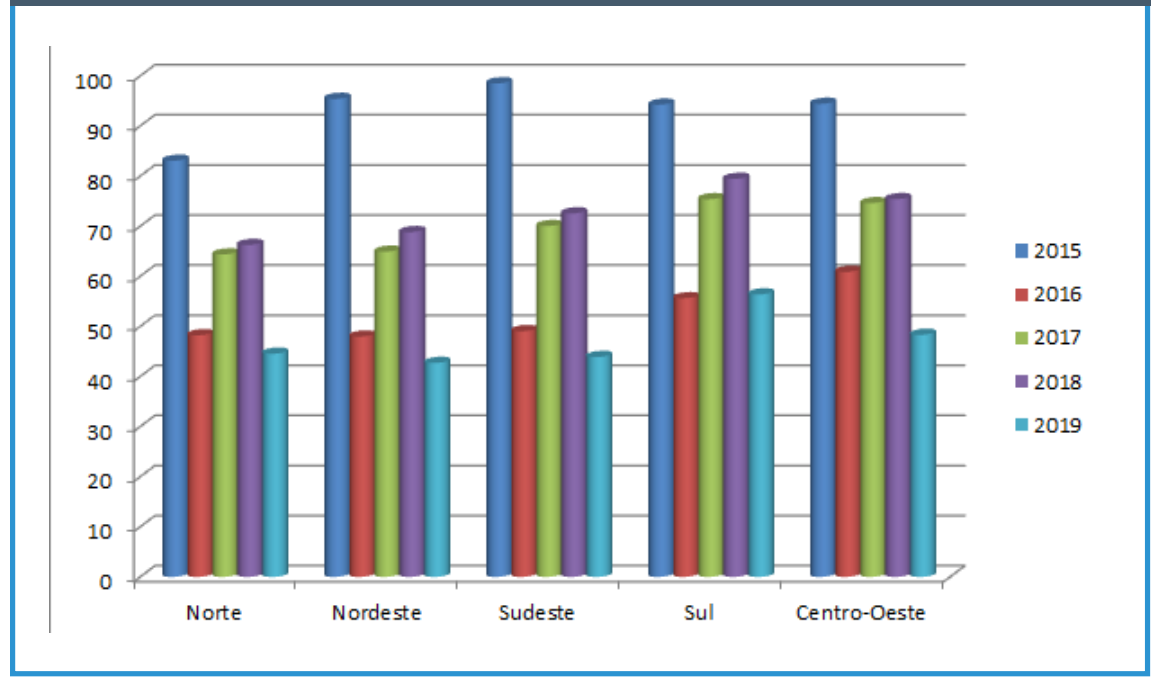

Fonte: DATASUS, 2020.

\section{FIGURA 3: Média de Cobertura Vacinal dos Estados, entre 2015 e 2019}

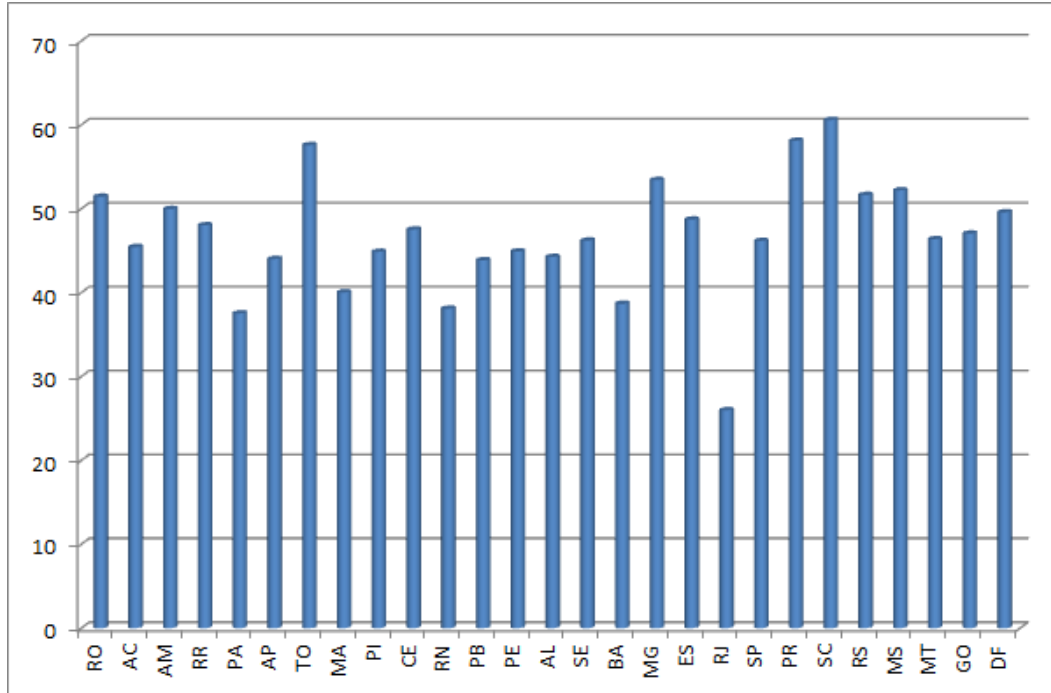

Fonte: DATASUS, 2020.

$(38,1 \%)$ e Ceará $(47,53 \%)$ possuem sequentemente menor e maior média da Grande Região Nordeste. Na Região Centro-Oeste, a maior média obteve-se no estado do Mato Grosso do Sul (52,21\%), e em Goiás (47,04\%) a menor média (FIGURA 3).

\section{Cobertura Por Imunobiológico}

Apesar da atualização do calendário nacional de vacina ser anual, no decorrer dos últimos cinco anos, vinte imunobiológicos são comuns entre os calendários analisados possibilitando o alcance das médias por imunobiológico entre $2015 \mathrm{e}$ 2019. Nesse período, a vacina BCG oferecida ao nascer, idealmente nas primeiras vinte e quatro horas de vida, teve a maior média de cobertura entre os imunobiológicos, com $89,68 \%$. A Hepatite B é uma outra vacina que deve ser oferecida ao nascer, e teve média 78,58\% (taxa de aplicação em até 30 dias de vida). Outras vacinas compõe o calendário da crianças e expressaram suas respectivas médias, como Rotavírus Humano (82,24\%), Hepatite A (77,19\%), Febre Amarela (47,13\%) que em 2020 passou a participar o calendário habitual de 1.101 municípios dos estados do Nordeste que ainda não faziam parte da área de recomendação de vacinação, e tendo uma dose de reforço aos 4 anos de idade, além da primeira dose aplicada ainda aos nove meses ${ }^{(8-9)}$.

As vacinas com esquemas integrado de mais de uma dose, como a Tríplice Viral, com média de $86,28 \%$ na $1^{\text {a }}$ dose, e $2^{\text {a }}$ dose $71.59 \%$, e reforço com Tetra Viral $(49,63)$, demonstrou declínio entre primeira dose e reforço, como a Meningococo $\mathrm{C}$, com $1^{\text {a }}$ dose $(83,61 \%)$ e a $2^{\text {a }}$ dose $(79,74 \%)$, a Pneumocócica inicialmente com média $85,73 \%$, e $2^{\text {a }}$ dose $76,52 \%$, Poliomielite ( $1^{\text {a }}$ dose $81,34 \%$; Reforço 70,94\%), e o esquema de Penta (81,23\%), DTP $(81,52 \%)$ e reforço com Tríplice Bacteriana (66,10\%), também seguiram em declínio nas doses de reforços.

O imunobiológico também componente do calendário de vacina do adulto e da gestante, que previne a Hepatite B $(87,61 \%)$ obteve a segunda maior média de cobertura vacinal, diferente da dTpa, 
vacina específica para gestantes, que demonstrou apenas 45,23 de média. O imunobiológico Dupla Adulto, apresentou a menor abrangência dentre todas as vacinas, com média de apenas $37,88 \%$ de cobertura (FIGURA 4).

\section{DISCUSSÃO}

Os resultados revelam que a cobertura nacional de vacinação realizada pelo PNI desde 2015 vem sendo variada, expondo resultados baixos não lineares, por vezes reagentes, mas, logo decrescentes, mantendo afastados da taxa de cobertura de vacinação preconizada O observado no cenário nacional referente a imunização durante os anos de 2015 a 2019, corrobora com o obtido nas análises feitas em cada região do país, onde a maior média alcançada entre as regiões durantes os últimos cinco anos, não chega a $75 \%$, sendo 66,43\% a média conquistada pelo país, semelhante a maior média atingida entre os estado (60,59\%).

A política de imunização conquistada e consolidada pelo Brasil é referência em todo mundo por sua cobertura, se tratando de um país populoso e territorialmente extenso, além de conter cenários geográficos e socioeconômicos diversificados. Entretanto, o panorama identificado na pesquisa não é exclusividade nacional, muito menos das Américas. Uma análise da cobertura de vacinação para a seguridade da saúde pública nacional.

de rotina global realizada em 2018, feita com base em análises realizadas após o Plano Global de Ação para Vacinas 2011-2020 - GVAP identificou que menos de dois terços de todos os países alcançaram globalmente a meta de $\geq 90 \%$ de cobertura nacional as taxas de primeiras doses de várias vacinas (que possuem mais de uma dose em seu esquema) contidas em comum em diversos países aumentaram, porém as demais doses permanecem em baixos níveis de cobertura, $60 \%$ de crianças que não receberam a $3^{\circ}$ dose DTP, ou nenhuma dose da mesma ( $54 \%$ a 97\%) em 2018, foram de 10 países, incluindo o $\mathrm{Brasil}^{(10)}$.

Um estudo ecológico realizado com informações do número crianças de até um ano de idade imunizadas com as vacinas BCG, poliomielite e tríplice viral, entre os nãos de 2006 e 2016, nos municípios brasileiros, observou uma redução no número de imunizações no Brasil tendenciosa, mostrando quedas de $0,9 \%, 1,3 \%$ e $2,7 \%$ ao ano para estas vacinas, respectivamente, transparecendo também, reduções temporais da cobertura vacinal entre as cinco regiões do Brasil, sendo convergente aos resultados obtidos entre os anos de 2015 e 1019. O mesmo estudo destaca uma heterogeneidade na redução na cobertura vacinal entre os municípios nos últimos anos, constatando a pluralidade de cenários entre os mesmos, indicando assim, a necessidade de planejamento e execução da atenção baseada nas necessidades locais

\section{FIGURA 4: Cobertura Vacinal Por Imunobiológico, entre 2015 e 2019}

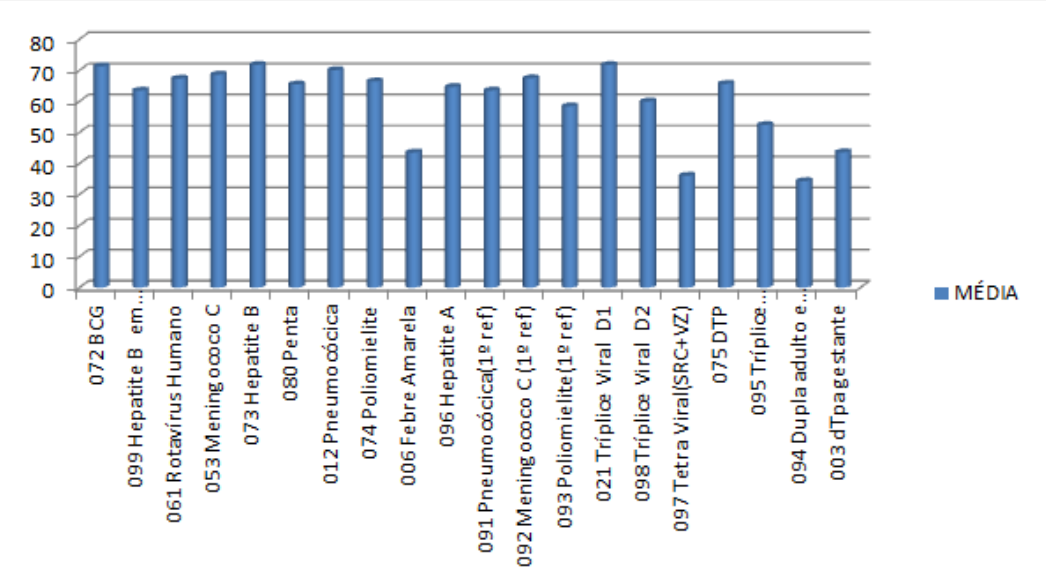

Fonte: DATASUS, 2020. de cada município, promovendo a cobertura vacinal adequada, bem como o controle do reaparecimento de doenças no Brasil ${ }^{(11)}$.

Um estudo realizado do Município de Araraquara, no interior do Estado de São Paulo, utilizando informações de vacinais de crianças até 24 meses de idade, vacinadas no município entre 1998 e 2013 analisou que a cobertura vacinal oportuna, ou seja, quando a vacina é administrada dentro o seu prazo preconizado perante a idade da criança, manifestou mínima de 53,33\% no ano de 2000 e máxima de 74,04\% em 2006, nas crianças de até 12 meses, demostrando porcentagem semelhante nas crianças de até 24 meses, com mínima de 36,78\% em 2011 e máxima de $53,83 \%$ no ano de 2006. Evidenciando congruência nos resultados obtidos nas medias manifestada entre as Regiões e Estados do Brasil nos anos de 2015 a $2019^{(12)}$.

Os motivos pelos quais justificam esse painel já vem sendo discutido no Brasil. Aqui o sucesso do programa pode ser uma das causas da queda da cobertura, pelo fato de que as pessoas com até 50 anos não presenciaram as sequelas deixadas nas vítimas infectadas pelas doenças já erradicadas pela atuação eficaz do PNI. Outra questão que é citada, é o desconhecimento real dos benefícios de saúde pública associados à imunização e a disponibilidade de vacinas noSUS, bem como a processo rígido de validação e de controle de qualidade em que os imunobiológicos sofrem pelas agências reguladoras e pelo próprio PNI. Fator o qual deixa a população vulnerável a ser convencida por movimento antivacinação disseminadores de fake news, sem qualquer fundamentação científica verídica ${ }^{(13)}$.

Esse desserviço e desorientação prestados à população em relação a imunização ou vacinação, são cada vez mais comuns nas chamadas redes sociais, corroborando para o movimento antivacina. Pesquisas já apontam para uma atuação prioritariamente em grupos fechados em aplicativos tipo Facebook e no WhatsApp, despertando a necessidade de direcionar novos estudos que atentem para esses outros espaços midiáticos. Deste modo evidencia-se que órgãos de ciência e saúde, assim como instituições governamentais, precisam investir em iniciativas neste âmbito para ampliar a interação com a população, tendo em 
vista que possuem um papel importante nesse diálogo entre ciência e sociedade. ${ }^{(14)}$

\section{CONCLUSÃO}

O estudo realizou uma análise descritiva da cobertura vacinal executada pelo PNI entre os anos de 2015 e 2019, identificando as baixas coberturas prevalentes em todos os estados entre as diferentes regiões no país, refletindo um grande problema de saúde pública, capaz de comprometer o controle de diversas doenças, e pôr em insegurança o consolidado e exemplar sistema de vacinação brasileiro.

O cenário descrito e avaliado no estudo aponta para a necessidade de aprimorar a comunicação entre profissionais e a população, especialmente com o público jovem, não só nas unidades de saúde, mas também nas instituições de ensino, grandes empresas e reunióes da sociedade civil, captadas pelos Agentes Comunitários de Saúde, a fim de unificar e promover informações corretas e seguras, semeadas pela equipe da ESF, além de estimular o hábito de frequentar Unidades Básicas de Saúde da Família - UBSF. -

\section{REFERÊNCIAS}

1. 1. F. [Bases Imunológicas da Vacinação]. Coleção Febrasgo - Vacinação da Mulher. 2015. Acesso em: 29 out 2020. Disponivel em: https://integrada.minhabiblioteca.com.br/\#/ books/9788595154865/.

2. Brasil. Ministério da Saúde. Secretaria de Vigilância em Saúde. Departamento de Imunização e Doenças Transmissiveis. Manual dos Centros de Referência para Imunobiológicos Especiais [recurso eletrônico] / Ministério da Saúde, Secretaria de Vigilância em Saúde, Departamento de Imunização e Doenças Transmissíveis, Coordenação-Geral do Programa Nacional de Imunizações. 5. ed. - Brasília : Ministério da Saúde, 2019. Acesso em: 29 out 2020. Disponivel em: https://portalarquivos2.saude.gov.br/images/pdf/2019/dezembro/11/manual-centros-referencia-imunobiologicos-especiais-5ed.pdf

3. Yokokura Ana Valéria Carvalho Pires, Silva Antônio Augusto Moura da, Bernardes Ariane Cristina Ferreira, Lamy Filho Fernando, Alves Maria Tereza Seabra Soares de Brito, Cabra Nayra Anielly Lima et al. Cobertura vacinal e fatores associados ao esquema vacinal básico incompleto aos 12 meses de idade, São Luís, Maranhão, Brasil, 2006. Cad. Saúde Pública [Internet]. 2013 Mar [cited 2020 Sep 30] ; 29( 3): 522-534. Acesso em: 01 ago 2020. Disponivel em <http://www.scielo.br/scielo.php? script=sci_arttext\&pid=S0102-311X2013000300010\&lng=pt\&nrm=iso >.

4. Queiroz Lorena Lauren Chaves, Monteiro Silvio Gomes, Mochel Elba Gomide, Veras Maria Amélia de Sousa Mascena, Sousa Francisca Georgina Macêdo de, Bezerra Márcio Lee de Meneses et al . Cobertura vacinal do esquema básico para o primeiro ano de vida nas capitais do Nordeste brasileiro. Cad. Saúde Pública [Internet] 2013 Feb [cited 2020 Sep 30] ; 29(2):294-302. Acesso em: 01 ago 2020. Disponivel em <http://www.scielo.br/scielo.php?script=sci _ arttext\&pid=S0102-311X2013000200016\&lng=pt\&nrm=iso > .

5. Ministério da Saúde. Programa Nacional de Imunizações: 40 anos. [publicação online] 2013. Acesso em: 01 ago 2020. Disponivel em: https://bvsms.saude.gov.br/bvs/publicacoes/programa_nacional_imunizacoes_pni40.pdf

6. Departamento de Informática do SUS - DATASUS. Cobertura Vacinal - Brasil. [publicação online] 2019. Acesso em: 01 ago 2020. Disponivel em: http://tabnet.datasus.gov.br/cgi/tabcgi.exe?pni/cnv/cpniuf.def.

7. Ministério da Saúde. Cresce 18\% número de casos de sarampo no Brasil. [publicação online] 2019. Acesso em 02 ago 2020. Disponível em: https://www.saude.gov.br/noticias/agencia-saude/45750- cresce-18-numero-de-casos-de-sarampo-no-brasil.

8. Ministério da Saúde. Ações contra surto buscam garantir recertificação de país livre do sarampo. [publicação online] 2019. Acesso em: 02 ago 2020. Disponível em: https://saude.gov.br/noticias/ agencia-saude/45304-acoes-contra-surto-buscam-garantir-recertificacao-de-pais-livre-do-sarampo.

9. Ministério da Saúde. Em 2020, Ministério da Saúde amplia público para vacinas contra febre amarela e gripe. [publicação online] 2020. Acesso em: 01 ago 2020. Disponivel em: https://www. saude.gov.br/noticias/agencia-saude/46139-em-2020-ministerio-da-saude-amplia-publico-para-vacinas-contra-febre-amarela-e-gripe.

10. Peck M, Gacic-Dobo M, Diallo MS, Nedelec Y, Sodha SS, Wallace AS. Global Routine Vaccination Coverage, 2018. MMWR Morb Mortal Wkly Rep [Internet]. 2019; 68: 937-942. Acesso em: 01 ago 2020. Disponivel em: https://pubmed.ncbi.nlm.nih. gov/31647786/.

11. Arroyo Luiz Henrique, Ramos Antônio Carlos Vieira, Yamamura Mellina, Weiller Teresinha Heck, Crispim Juliane de Almeida, Cartagena-Ramos Denisse et al . Áreas com queda da cobertura vacinal para BCG, poliomielite e tríplice viral no Brasil (20062016): mapas da heterogeneidade regional. Cad. Saúde Pública [Internet]. 2020 [cited 2020 Nov 01]; 36( 4 ): e00015619. Available from: http://www.scielo.br/scielo.php?script=sci_arttext\&pid=S0102-311X2020000405003\&Ing=en. Epub Apr 06, 2020. https://doi.org/10.1590/0102-311x00015619.

12. Ferreira, Vinicius Leati de Rossi et al. Avaliação de coberturas vacinais de crianças em uma cidade de médio porte (Brasil) utilizando registro informatizado de imunização. Cadernos de Saúde Pública [online]. 2018, v. 34, n. 9 [Acessado 1 Novembro 2020] , e00184317. Disponivel em: <https://doi.org/10.1590/0102311X00184317>. Epub 06 Set 2018. ISSN 1678-4464. https:// doi.org/10.1590/0102-311X00184317.

13. Fundação Oswaldo Cruz. A queda da imunização no Brasil. [publicação online] 2017. Acesso em: 01 ago 2020. Disponível em: https://portal.fiocruz.br/documento/queda-da-imunizacao-no-brasil.

14. Fundação Oswaldo Cruz. Com fake news, discurso antivacina se espalha nas redes. [publicação online] 2017. Acesso em: 01 nov 2020. Disponivel em: https://portal.fiocruz.br/noticia/ com-fake-news-discurso-antivacina-se-espalha-nas-redes. 